\title{
Relação entre universal, particular e singular em análises feministas marxistas: por uma ontologia integrativa'
}

\author{
Relationship between universal, particular and \\ singular in marxist feminist analyzes: \\ by an integrative ontology
}

\section{Lívia de Cássia Godoi Moraes ${ }^{\mathrm{a}} \odot$}

\begin{abstract}
Resumo Este artigo, de base teórico-bibliográfica, tem por objetivodesenvolver, em defesa do método materialista histórico-dialético como arma teórica e política do feminismo marxista, a proposta de ontologia integrativa a partir da teoria unitária, alicerce da Teoria da Reprodução Social (TRS). Para tanto, apresentamos os embates em torno das aproximações e distanciamentos entre feminismo(s) e marxismo desde a década de 1970, bem como o diálogo crítico da TRS com os sistemas duplos e triplos. Analisamos um dos elementos que consideramos mais relevantes no método:a relação entre universal, particular e singular, pela chave da categoria totalidade. Tal relação nos permite, por um lado, enfatizar os desafios postos pela realidade no que concerne aos níveis de abstração na análise do concreto, síntese de múltiplas determinações;por outro, auxilia no desenvolvimento do diálogocrítico com a interseccionalidade e a consubstancialidade. Trata-se de um exercício teórico que enfatiza a categoria mediação (particularidade)como fundamental para pensar os desafios postos àsociabilidade generificada e racializada e a totalidade social capitalista, de uma perspectiva feminista marxista.
\end{abstract}

Palavras-chave Teoria de Reprodução Social. Feminismo marxista. Materialismo histórico-dialético. Totalidade. Mediação.

Abstract This theoretical-bibliographic article aims to develop, in defense of the historical-dialectical materialist method as a theoretical and political weapon of Marxist feminism, the proposal of integrative ontology from the unitary theory, the foundation of the Social Reproduction Theory (TRS). Therefore, we present the conflicts

1 Agradeço a leitura atenta e sugestões de Mariana Shinohara Roncato e ao debate coletivo do Grupo de Estudos sobre Teoria da Reprodução Social.

a Docente do Departamento de Ciências Sociais e do Programa de Pós-Graduação em Política Social da Universidade Federal do Espírito Santo. Coordenadora do Grupo de Pesquisa Trabalho e Práxis. Pesquisadora do Grupo de Estudos sobre Teoria da Reprodução Social. Email: liviamoraes@outlook.com 
around the approximations and distances between feminism(s) and Marxism since the 1970s, as well as the critical dialogue of TRS with the double and triple systems. We analyze one of the elements that we consider most relevant in the method: the relationship between universal, particular and singular, using the key of the totality category. This relationship allows us, on the one hand, to emphasize the challenges posed by reality with regard to the levels of abstraction in the analysis of the concrete, as synthesis of multiple determinations; on the other hand, it helps in the development of critical dialogue with intersectionality and consubstantiality. This is a theoretical exercise that emphasizes the mediation category (particularity) as fundamental to think about the challenges posed to gendered and racialized sociability and the capitalist social totality, from a Marxist feminist perspective.

Keywords Social Reproduction Theory. Marxist feminism. Dialectical-historical materialism. Totality. Mediation.

\section{FEMINISMO(S) E MARXISMO: ENCONTROS E DESENCONTROS}

Abreu e Castro (2019), ao resgatarem os encontros e desencontros entre marxismo, feminismo e sexualidade, na Revista Crítica Marxista, no dossiê "Marxismo, feminismos, queer e sexualidades - Parte I", afirmaram que a "questão feminina" é tema de autores e autoras marxistas desde o século XIX, com destaque para Engels, Bebel, Kollontai e Zetkin enquanto produtores/as de textos clássicos nessa temática.

Nas décadas de 1960-1970, quando novos movimentos de esquerda despontavam no horizonte como "uma nova esquerda", que, em grande parte, questionava o economicismo, o estruturalismo e o etapismo de caráter manualesco nos partidos comunistas, as mulheres ainda experienciavam opressões no interior dos movimentos e partidos de esquerda. Isto posto, decidiram se organizar em grupos, organizações e movimentos sociais de lutas especificamente feministas.

De forma mais crítica ou numa tendência de atualização, o marxismo foi reivindicado por feministas radicais, materialistas, socialistas e marxistas ${ }^{2}$. Porém, as diferenças sobre como se apropriar do marxismo ${ }^{3}$ marcaram mais fortemente $o$

2 Para compreender melhor as diferenças entre correntes de feminismos anticapitalistas, ver Moraes e Esquenazi (2020).

3 Essa dificuldade em como se apropriar do marxismo tem relação com as diversas leituras de Marx no interior do marxismo, algumas mais estruturalistas, outras mais dialéticas. Apesar de utilizarmos aqui marxismo - no singular - temos ciência da diversidade de leituras no interior da teoria marxista. É importante evidenciar também que marxismo e feminismo estão em níveis de abstração diferentes. De um lado, uma teoria, o marxismo, de outro, feminismo enquanto movimento que se expressa na realidade concreta como uma práxis, cujas correntes se assentam em bases teóricas bastante diversas, tais como liberalismo e socialismo, por exemplo. 
debate teórico com implicações para lutas sociais a partir de meados da década de 1970, e, especialmente, na década de 1980, período em que muitas feministas internalizaram esse debate para o meio acadêmico, institucionalizando os chamados estudos de gênero.

A queda do muro de Berlim e o fortalecimento do neoliberalismo na década de 1980 marcaram, contudo, um afastamento do marxismo tanto nos meios acadêmicos quanto na luta política.

Neste contexto, tornou-se quase axiomático que acadêmicos e ativistas dispensassem o marxismo em geral - e a economia política marxiana em particular - como um quadro explicativo datado, irremediavelmente reducionista, inadequado para a construção de uma teoria abrangente da opressão às mulheres. Ao mesmo tempo, o punhado de grupos de extrema esquerda que insistiam no contrário, com frequência defendia ortodoxias passadas, mostrando uma indisposição para reconhecer que o materialismo histórico precisava reavaliar sua análise da opressão às mulheres na sociedade capitalista (Ferguson; Mcnally, 2017, p. 31).

Somente ao final da primeira década do século XXI ocorreu um reavivamento mais contundente do marxismo e, passados quarenta anos da efervescente contenda, muitos dilemas sobre a relação entre marxismo(s) e feminismo(s) ainda estão por serem debatidos.

Ao longo do mencionado recorrido histórico, contudo, foi mantida uma disposição das feministas marxistas em atualizar suas análises sem perder de vista o método. Aqui, neste artigo de base teórico-bibliográfica, nosso objetivo é ressaltar como fundamental para análises feministas marxistas, um dos elementos que consideramos mais relevantes no materialismo histórico-dialético: a relação entre universal, particular e singular, sob a chave da categoria totalidade. A defesa do método, assim, é também a defesa de uma práxis política transformadora e emancipatória.

Para tanto, fazemos uma explanação da importância de compreender a relação dialética entre universal, particular e singular no método de Marx, sob uma ótica lukacsiana, no sentido de corroborar com as críticas que as pesquisadoras e femi-

Segundo Vogel (2018), o mesmo ocorre com as dimensões da diferença "raça, classe e gênero": a busca por similaridades ou paralelismos minimiza as particularidades. Assim sendo, o debate é extremamente desafiador e, por isso mesmo, até o momento, inconcluso. 
nistas da Teoria da Reprodução Social (TRS) ${ }^{4}$ vêm fazendo aos sistemas duplos e triplos concernentes às conceituações de interseccionalidade e consubstancialidade, tendo por base a ontologia integrativa, conforme defende Ferguson (2017). Trata-se de um exercício teórico que enfatiza a categoria mediação como fundamental para pensar os desafios postos à sociabilidade generificada e racializada em relação à totalidade social capitalista fetichizada.

\section{O UNIVERSAL, O PARTICULAR E O SINGULAR EM MARX E LUKÁCS}

Pelo fato de Karl Marx ter feito poucas e breves sistematizações sobre seu método, sendo o item mais lido "O método da economia política", constante no livro Grundrisse (2011), há muitos debates e disputas entre os/as marxistas sobre o que seria o método, com ênfase na diferenciação entre análises mais estruturalistas e análises mais dialéticas.

Nossa leitura do método de Karl Marx reivindica a dialética. Pensamos ser de fundamental relevância não se perder na relação entre universal, particular e singular. Um capítulo primordial, para nós, é "O particular à luz do materialismo histórico dialético", de Lukács (1970).

O debate feminista, enquanto teoria e práxis, parece, em nossa leitura, ratificar a importância dos elementos acima indicados para análise, especialmente no que diz respeito ao imbróglio que envolve classe, raça e gênero/sexo/sexualidade 5 . Tanto boa parte das análises interseccionais quanto as consubstancialistas consideram que não se deve perder de vista tais elementos nas análises.

A Teoria da Reprodução Social, especialmente nas produções recentes (Arruzza, 2019; 2017; 2015; Ferguson, 2017), vem se debruçando em fazer a crítica aos

4 A Teoria da Reprodução Social é de base marxista, mas pretende avançar na análise das questões de gênero. Tal teoria parte do princípio de que a produção de bens e serviços e a produção da vida são parte de um mesmo processo, um processo integrado (Bhattacharya, 2019). Destacam-se como importantes pesquisadoras/es nesse campo: Lise Vogel, Martha Gimenez, Johanna Brenner, Susan Ferguson, David McNally, Cinzia Arruzza e Tithi Bhattacharya. "A TRS nasce, no século XXI, a partir de um movimento de convergência entre diversas intelectuais feministas-marxistas que desde o final do século XX vinham se engajando no desenvolvimento da perspectiva unitária no sentido de uma maior aproximação com a realidade concreta. Estas intelectuais incorporavam em sua teorização, estudos empíricos e ativismo muitos dos questionamentos, demandas e horizontes dos movimentos feministas, antirracistas, pós-coloniais e queer. Este diálogo possibilitou que estas intelectuais suprissem as lacunas da obra de Vogel (2013), propondo um reposicionamento do campo marxista em relação aos debates sobre classe, opressões, identidades e a questão ambiental. Isto traduz um esforço de recuperar e desenvolver a teoria de Marx na direção específica de compreender a conexão entre as relações sociais econômicas e extraeconômicas, destacando como as categorias de opressão são produzidas de forma simultânea e imbrincada à produção de mais-valia e, assim, não podem ser hierarquizadas" (Ruas, 2021, p. 400-1). Consideramos que a teoria segue em processo de construção, mas tem bases sólidas no método materialista histórico-dialético.

5 O debate em torno do uso dos conceitos sexo e gênero podem ser encontrado em Cisne (2014), Scott (2019) e Devreux (2005). 
sistemas duplos ou triplos a partir de análises rigorosamente calcadas em bases ontológicas ${ }^{6}$.

Lukács (1970, p. 68) afirmou que, para uma compreensão materialista dialética do concreto, é preciso, em primeiro lugar, afastar o empirismo, por um lado, e o idealismo, por outro. $\mathrm{O}$ concreto não deve ser confundido com o fenomênico e se bastar nele. $\mathrm{O}$ concreto é síntese de múltiplas determinações, a unidade da diversidade, conforme Marx (2012). Ele é, ao mesmo tempo, resultado e ponto de partida da análise.

Em princípio, se expressa em representação, mas a análise marxista deve buscar a essência, ou seja, as determinações múltiplas do concreto, na perspectiva da totalidade.

A economia começa, por certo, com a indagação da 'viva totalidade' da sociedade, mas seu desenvolvimento como ciência expressa-se precisamente no fato de que ela elabora, através da abstração e da análise, 'algumas relações determinadas, abstratas, universais'. Apenas por este caminho pode a ciência econômica retornar destas determinações simples e universais à totalidade da realidade, que precisamente agora pode ser conhecida como realidade autêntica e concreta (Lukács, 1970, p. 68).

E Lukács (1970, p. 76, grifo nosso) recorre a Hegel para tal sugestão epistemológica: "Foi, em seu tempo, uma importante realização de Hegel, ter tratado de um problema exclusivamente lógico em aparência, como é o caso da relação do universal com o particular e o singular, como um problema da estrutura e do desenvolvimento da sociedade".

A mediação entre universalidade e singularidade é a particularidade. Conforme Mészáros (2013, p. 58) explica, “totalidade social' sem 'mediação' é como 'liberdade sem igualdade': um postulado abstrato - e vazio”. Duas ameaças, ao recair nos extremos, são apontadas por Mészáros (2013, p. 58): por um lado, "a mistificação da totalidade como imediaticidade", ou seja "a negação da mediações e interconexões complexas", que podem produzir mitos perigosos, como foi/é o caso do nazismo; por outro lado, "o culto da imediaticidade e a negação da totalidade", que podem produzir “a desorientação, a defesa da fragmentação, a psicologia da insignificância

6 Diferente de análises antropológicas, prevalecentes, por exemplo, nas análises das feministas materialistas francesas. Markus (2015) alerta que uma antropologia sem o materialismo histórico-dialético pode produzir uma essência humana estática e a-histórica. 
de nossas ações, a rejeição cínica da atividade inspirada pela moral e a aceitação impotente de nossas condições".

Esse exercício de analisar via mediações é verificado na crítica da economia política. Marx está se contrapondo à máxima da economia política clássica de que o capital é uma relação eterna, portanto universal, o que só faz sentido se se desconsiderar a relação dialética da universalidade com a particularidade.

O capitalismo, ele mesmo, é uma forma particular de modo de produção, determinado pelo desenvolvimento histórico, que não é linear, mas contraditório, com forças produtivas e relações de produção peculiares, de caráter transitório, exatamente por ser historicamente determinadas. Ao mesmo tempo, o capitalismo é uma totalidade social.

Marx (2013), em "O Capital", faz importantes distinções entre o que seja capital em geral e o capital particular, e trabalho em geral e trabalho particular. Essa diferenciação requer também a distinção em níveis de abstração da análise: mais abstrato ou mais concreto, sem nunca perder de vista que um nível de análise não deve excluir o outro para suas conclusões teóricas - num sentido sempre de tendência, porque é histórico, portanto, transitório.

Jacob Gorender (2013, p. 36), na apresentação do livro "O Capital" da edição brasileira da Editora Boitempo, explicou como a análise do capital é feita em diferentes níveis de abstração na própria estrutura do livro. "O 'capital em geral'é, segundo Marx, a 'quintessência do capital', aquilo que identifica o capital enquanto capital em qualquer circunstância”. No Livro I, o desenvolvimento de Marx se centrou na exploração da força de trabalho assalariada, tendo sido a fábrica o locus principal de análise. Já no livro II, Marx trata da circulação e da reprodução do capital social total. No referido livro, o "capital é sempre plural, múltiplo, mas circula e se reproduz como se fosse um só capital social”, ou seja, há uma necessidade de avançar na relação entre particular e universal para o desdobramento teórico do Livro II. "No Livro III, os capitais se diferenciam, se individualizam, e o movimento global é enfocado sob o aspecto da concorrência entre os capitais individuais", sem perder de vista o movimento do capital em geral.

De acordo com as funções específicas que desempenham no circuito total da economia capitalista - na produção, na circulação e no crédito -, os capitais individuais apropriam-se de formas distintas de mais-valia: lucro industrial, lucro comercial, juros, cabendo à propriedade territorial a renda da terra, também ela uma forma particular da mais-valia. A lei dinâmica direcionadora desse embate 
concorrencial entre os capitais individuais pela apropriação da mais-valia é a lei da queda tendencial da taxa média de lucro (Gorender, 2013, p. 36).

O exercício de observar a relação dialética entre universal, particular e singular se complexifica ao longo do desenvolvimento teórico de O Capital. E é fundamental buscar compreender como as transformações históricas concretas modificam a relação dialética entre universal e particular, entre o capital em geral e os capitais particulares.

Do mesmo modo que ocorre com o capital, ocorre com o trabalho. O trabalho do ser social em seu caráter ontológico, que transforma conscientemente a natureza, via pores teleológicos, é universal. Todo ser social se constitui enquanto ser social via trabalho. Mas, no modo de produção capitalista, o trabalho adquire uma particularidade, a de poder se apresentar como trabalho humano abstrato, indiferenciado, que cria e valoriza valor. Esse trabalho vive uma relação de unidade contraditória com suas formas singulares de trabalho, o trabalho concreto, que, ao produzir valores de uso diversificados, potencializam, no mercado de trocas capitalista, a realização via o valor de troca, que não é senão a manifestação do valor.

Assim, a mercadoria também expressa a relação contraditória entre universalidade e particularidade: a universalidade de se expressar enquanto valor de troca e a sua particularidade enquanto produto do trabalho concreto.

Aqui é preciso atentar para o fato de que há elementos naturais e elementos sociais na análise. Mulheres e homens, para existirem, atuam sobre a natureza, mas atuam de forma específica a partir do desenvolvimento sócio-histórico de seu tempo. E é o caráter social do intercâmbio de mercadorias que cria generalizações superiores, leis (enquanto tendências), que, apesar de generalizadas, são particulares daquele espaço temporal e geográfico, histórica e culturalmente determinados.

A mais-valia é, portanto, produto histórico das relações desenvolvidas no modo de produção capitalista. E a sua generalização se efetiva no pensamento humano quando reproduz o que foi produzido pelo desenvolvimento histórico-social. Assim, “[...] a explicitação da forma valor, devida ao desenvolvimento econômico real eleva-se - na realidade objetiva - da singularidade à universalidade através da particularidade" (Lukács, 1970, p. 91).

O desenvolvimento feito até aqui deverá nos auxiliar, na seção seguinte, na análise crítica dos sistemas duplos e triplos, com base na Teoria da Reprodução Social, que defende que é preciso olhar para a diversidade como unidade do diverso, síntese de múltiplas determinações, sem colocar como polos opositores a identidade e a diferença. 
O método, que pensa a particularidade como mediação, não perde de vista as relações internas, a historicidade, a totalidade social, ainda que seja difícil o exercício de olhar para a realidade - diversa e una - pela via de níveis de abstração, do concreto ao mais abstrato e, de volta, do mais abstrato ao mais concreto, porém, já repleto de determinações e explicitada sua essência.

Isso é exatamente o que a 'teoria unitária' tenta alcançar: ser capaz de interpretar as relações de poder baseadas no gênero ou orientação sexual como momentos concretos daquela totalidade articulada, complexa e contraditória que éo capitalismo contemporâneo (Arruzza, 2015, p. 57, grifos nossos)

O exercício da suprassunção, aprendido e apreendido de Marx, é o que propomos. Ou seja, de modo algum rechaçamos os sistemas duplos e triplos como construções importantes, tanto teoricamente quanto na práxis política, mas defendemos que a teoria unitária e a sua ontologia integrativa propõem, a um só tempo, "a eliminação, a conservação e a sustentação qualitativa do ser que supra-sume”, conforme a explicação de Ranieri (2004, p. 16) sobre a tradução de Aufhebung por suprassunção.

\section{CRÍTICA AOS SISTEMAS DUPLOS E TRIPLOS}

\section{CAPITALISMO, PATRIARCADO E RACISMO ESTRUTURAL}

Desde a década de 1970, se discute a respeito dos "casamentos e divórcios" entre marxismo e feminismo7. O que permeia a discussão é o fato de que nas aproximações entre marxismo(s) e feminismo(s), em geral, a teoria marxista é prevalecente.

No referido debate, há a centralidade da relação entre capitalismo e patriarcado. Seriam dois sistemas em separado ou seria um único plano de debate para o qual se deveria considerar uma teoria unitária?

Heidi Hartmann (1983) faz longas exposições sobre como as feministas radicais pensavam patriarcado em esfera separada do capitalismo. A noção de patriarcado definida como a dominação masculina sobre as mulheres, por parte das feministas radicais, tem raízes biológicas, psicológicas e culturais. Tais proposições fazem recair em uma universalização histórica do patriarcado, como se fosse

7 Sínteses desse debate podem ser encontradas em Arruzza (2019) e Moraes (2021). 
"natural" da relação entre homens e mulheres, perdendo do horizonte de análise as particularidades históricas ${ }^{8}$.

Da mesma forma que os economistas políticos clássicos pensavam o capitalismo como natural e universal, assim o faziam as feministas radicais ${ }^{9}$ com relação ao patriarcado. Um universal desconectado das particularidades.

A centralidade da análise das feministas radicais estaria no político, ou seja, nas relações de poder e de dominação. Hartmann (1983) chama a atenção para a secundarização das bases materiais do patriarcado como, por exemplo, a divisão sexual do trabalho e o consequente impacto sobre o controle dos corpos das mulheres.

Diferentemente da teoria unitária, que não perde de vista a relação entre produção e reprodução, as feministas radicais focam o olhar na reprodução, e a produção, muitas vezes, desaparece do quadro de análise. "Ao proporem uma espécie de 'patriarcado puro', sem história, sem materialidade, acabaram por apagar as particularidades do patriarcado e, em especial, de desvendar quais os determinantes históricos do patriarcado no modo de produção capitalista” (Moraes, 2021, p. 93).

Ao reivindicar a base material do patriarcado, Hartmann (1983) tenta aproximar capitalismo e patriarcado, mas, segundo Young (1992), não consegue superar a duplicidade de sistemas. Para a mencionada autora, ainda que concorde com as críticas de Hartmann (1983) às feministas radicais, capitalismo e patriarcado continuam aparecendo como sistemas diversos, com leis próprias. Young (1992) afirma que, ao sinalizar para o fato de que o patriarcado não está apenas dentro do lar, no espaço privado, mas também alcança o trabalho e o espaço público, torna difícil analisá-los em separado.

Os riscos de equívocos prático-políticos são muito grandes quando se faz a análise a partir de sistemas duais. A feministas materialistas francesas, com especial destaque para Delphy (2015), chegaram a supor um modo de produção patriarcal em paralelo ao modo de produção capitalista. A questão da dominação do homem sobre a mulher, que se configuraria como um novo modo de produção, leva a que essas autoras criem o conceito de "classe de sexo".

Para Young (1992), há um só modo de produção em análise, o modo de produção capitalista, e, para a autora, a categoria trabalho, fundante desse modo de

8 Hartmann (1983) está dialogando mais diretamente com Juliet Mitchell e Shulamith Firestone.

9 Importante ressaltar que no interior do Feminismo Radical há uma grande heterogeneidade, prevalecendo a centralidade da relação de dominação dos homens sobre as mulheres. Destacam-se Kate Millet, Juliet Mitchell e Shulamith Firestone. 
produção e do patriarcado, possibilita com que produção e reprodução não sejam pensadas em separado, garantindo, assim, uma teoria unitária de capitalismo e patriarcado. As mulheres, nesse sistema, seriam forças de trabalho secundárias requeridas ou repelidas pelos ditames do capital.

Assim como para Hartmann (1983), Young (1992) preza pela relação entre universal e particular. Porque não basta entender que a divisão sexual do trabalho impõe a condição marginalizada de trabalho às mulheres, dentro e fora do lar, mas faz-se necessário pensar a particularidade não só dessa relação no modo de produção capitalista, como também que outras particularidades perpassam a condição de vida das mulheres a partir de sua origem étnica, da condição de desenvolvimento de seu país, de sua raça etc. E, para Young (1992), no nível da práxis, seria impossível realizar lutas anticapitalistas e antipatriarcais em separado. A luta é a mesma, porque o sistema é um só.

A década de 1990 é marcada, no campo teórico da pós-modernidade, como a década da morte do marxismo, com a queda do muro de Berlim, o chamado fim do socialismo real, que se desdobrou em fim da história, que se encerra no próprio capitalismo.

Mas, nos anos 2000, especialmente com a crise que se expressou de forma mais explícita na sua esfera financeira, Marx volta ao cenário enquanto teórico da crise capitalista e, novamente, a classe trabalhadora passa a fazer parte dos embates teórico-políticos com mais recorrência.

Nessa seara, Arruzza (2019) recupera o debate da relação entre marxismo e feminismo com vistas a alicerçar a prática política no século XXI e, ao invés de casamentos e divórcio, aponta para uma "união queer" entre feminismo e marxismo.

Quando Arruzza (2019) fala de união queer, ela está se referindo às tentativas equivocadas de fazer do gênero uma classe ou da classe um gênero, pulverizando relações pessoais e as reduzindo a opressões singulares, a esperar um espaço na fila pela inclusão no projeto de emancipação (Moraes, 2021, p. 102).

Arruzza (2019), assim como Young (1992), defende uma teoria unitária e toma a articulação entre produção e reprodução social como central, buscando não recair nas "armadilhas dos dualismos" (Arruzza, 2017, p. 41). Tal concepção avança também para análise dos sistemas triplos, que reúnem, além de classe e gênero, a questão racial.

Ferguson (2017, p. 19-20), no mesmo sentido de Arruzza (2017; 2019), compreende que as diferentes opressões são irredutíveis umas às outras, dado que não 
são idênticas, mas que é necessário explorar uma "relação interna entre relações parciais e totalidade social". Essa relação entre particularidade das opressões e totalidade social capitalista é o que desenvolveremos adiante. Porém, antes disso, consideramos relevante apresentar brevemente o debate entre interseccionalidade e consubstancialidade.

\section{INTERSECCIONALIDADE E CONSUBSTANCIALIDADE: DISTANCIAMENTOS E APROXIMAÇÕES}

Collins (2017) chama a atenção para o fato de que, com frequência, as narrativas contemporâneas que reivindicam a interseccionalidade ignoram que sua raiz está no movimento social, especialmente no feminismo negro, dos anos 1960 e 1970, nos Estados Unidos.

Segundo a estudiosa, é no contexto de efervescência social que as feministas afro-americanas constataram que só era possível falar de opressão adotando perspectivas de raça, classe, gênero e sexualidade como sistemas de intersecção de poder. Tratava-se de um sistema múltiplo e simultâneo de opressões.

Tomando uma postura implicitamente interseccional em relação à emancipação de mulheres afro-americanas, mulheres afro-americanas de diversas perspectivas políticas apresentaram ensaios provocativos sobre como as mulheres negras nunca ganhariam sua liberdade sem perceber sua raça, classe e gênero (Collins, 2017, p. 8).

O Manifesto do Coletivo Combahee River também é um marco, porque expressa pautas de um coletivo de feministas negras e lésbicas que se reuniu de 1974 a 1980, em Boston, Estados Unidos, para realizar atividades políticas junto com organizações e movimentos progressistas. O manifesto de 1977 afirmava:

[...]nossa política atual é a de que estamos ativamente comprometidas com a luta contra a opressão racial, sexual, heterossexual e de classe; encaramos como nossa tarefa particular o desenvolvimento de análise e práticas integradas baseadas no fato de que os principais sistemas de opressão estão interligados (Combahee River, 1977, p. 197, grifo nosso).

Elas asseveravam, no manifesto, que as mulheres negras trabalhadoras sempre estiveram no movimento feminista, especialmente as de países periféricos, mas que forças reacionárias, elitistas e racistas dentro do próprio movimento ofuscaram 
a participação dessas mulheres, por isso a necessidade de organizar o grupo de feministas negras em separado das não-negras.

Collins (2017) alerta para o fato de que as feministas negras não estavam sós nessa pauta, mas também as latinas residentes dos Estados Unidos estavam engajadas em lutas intelectuais e políticas semelhantes.

Hirata (2014), ao tratar dos temas de interseccionalidade e consubstancialidade, diz que há algo em comum nessas conceituações: partem de um pressuposto importante para as teóricas feministas, de que o "conhecimento situado", ou seja, ser mulher na sociedade capitalista, ser mulher negra, ou mulher latina, ou mulher indígena, ou mulher do Oriente, dentre outros, tem implicações sobre como se faz ciência.

Daí a afirmação das feministas negras do Combahee River (2019, p. 198): "é inegável, também, a existência de uma gênese pessoal para o feminismo negro, isto é, a percepção política que vem das experiências aparentemente pessoais da vida individual de mulheres negras".

Apesar de já estar expresso na prática política, nos manifestos políticos e na literatura, pensar as opressões de raça, classe e sexo de forma simultânea era de extrema relevância, e alcançou o mundo acadêmico. Essa relação virou conceito quando essas mulheres começaram a ocupar espaço na Academia, nas Universidades, especialmente na década de 1980.

Segundo Collins (2017, p. 8, grifo nosso): "essas ideias chegaram à academia inicialmente sob a rubrica de estudos de raça/classe/gênero e subsequentemente foram nomeadas e legitimadas como interseccionalidade".

O conceito de interseccionalidade foi cunhado por Kimberlé Crenshaw, uma teórica crítica da questão racial, advogada e defensora de justiça social em fins da década de 1980 e na década de 1990. O marco é o ensaio "Demarginalizing the intersection of race and sex: a black feminist critique and antidiscrimination doctrine", de 1989, reforçada pelo artigo "Mapeando as margens: interseccionalidade, políticas de identidade e violência contra mulheres não brancas"10, publicado originalmente na Stanford Law Review, em 1993.

Collins (2017) explica que o termo interseccionalidade foi/é importante, porque ganhou legitimidade acadêmica e visibilizou o debate que nasceu na prática política. Porém, apesar de manter o caráter de justiça social, em parte, se ajustou ao mundo acadêmico, ao invés de transformá-lo, como desejava a práxis política das feministas negras das décadas de 1960 e 1970. Collins e Bilge (2021, p. 117)

10 No Brasil, a tradução foi feita pelo site da Medium. 
afirmam, contudo, que essa crítica não deve romantizar o período pré-institucional, também "afetado pelas operações de poder do capitalismo e pelo Estado", e que, mesmo institucionalizado nas últimas décadas, há “contra-histórias”, que conectam interseccionalidade a movimentos sociais.

Crenshaw (1993) explicou que a relevância da interseccionalidade estava no fato de que ela buscava superar o debate que contrapunha identidade e diferença (ou essencialismo versus pós-modernidade). Ela argumentou que a categorização (mulher, negro etc.) é carregada de poder, mas que não se pode ignorar a agência do subordinado, que reverte significados, por exemplo, positivando a categoria "negro".

A interseccionalidade permite possibilidades de identidade significativas, combinando duas ou mais manifestações de poder separadas, mas intimamente ligadas. A estudiosa afirma que grupos de identidade podem agir por coalizões, por exemplo, "a interseccionalidade fornece uma base para reconceitualizar a raça como uma coalizão entre homens e mulheres não-brancos" (Crenshaw, 1993, s.p.) ou, outro exemplo, "a raça também pode ser uma coalizão de pessoas heterossexuais e homossexuais e assim servir como base para a crítica das igrejas e outras instituições culturais que reproduzem o heterossexismo" (Crenshaw, 1993, s.p.).

Já o conceito de consubstancialidade foi mobilizado pelas feministas materialistas francesas desde 1970-1980, em especial por Danièle Kergoat. Essa estudiosa propôs se contrapor ao que ela denominava noções geométricas: adição, intersecção e multiposicionalidade. E afirmou:

A minha tese é: as relações sociais são consubstanciais; elas formam um nó que não pode ser desatado no nível das práticas sociais, mas apenas na perspectiva da análise sociológica; e as relações sociais são coextensivas: ao se desenvolverem, as relações sociais de classe, gênero e "raça" se reproduzem e se co-produzem mutuamente (Kergoat, 2010, p. 94, grifos da autora).

O referido artigo, publicado no Brasil em 2010, segundo Hirata (2014), resultou de uma conferência de 2006, realizada por Kergoat em Grenoble, na França. Foi a primeira vez que a pesquisadora fez uma crítica direta à concepção de interseccionalidade.

A principal crítica ao conceito de interseccionalidade e em defesa da consubstancialidade por parte de Kergoat (2010) diz respeito ao fato de que as feministas que se utilizam teoricamente da interseccionalidade se centram nas categorias, perdendo de vista a relação social. A estudiosa chama a atenção para a importante distinção entre relação intersubjetiva e relação social. 
Kergoat (2010), ao fazer a crítica a Crenshaw (1993), valorizou o fato de que é importante pensar a posição dessas mulheres na sociedade (classe, raça, sexualidade etc.), porém, é preciso não perder de vista que essas posições não são fixas, e não apenas estão em coalizão umas com as outras, mas compõem relações sociais que estão em movimento na história.

Hirata (2014) chama a atenção para algo que muitas vezes não está explícito no debate entre interseccionalidade e consubstancialidade, que é o fato de que a primeira se centra mais na relação entre gênero e raça, secundarizando a classe, enquanto a segunda se centra mais em gênero e classe, secundarizando raça.

Roncato (2020) ainda chama atenção para a questão de que, em geral, quando a abordagem é interseccional, a concepção de classe social carece de precisão ${ }^{11}$, parece ser utilizada muito mais no sentido de estratificação social do que classe como fundante das relações sociais, como na perspectiva marxista.

Consideramos que esse debate fez avançar as análises feministas, de modo a não perder de vista a relação entre gênero, raça e classe em qualquer dos dois desenvolvimentos, quais sejam: interseccionalidade e consubstancialidade. Porém, ainda permanece uma diferença, porque nas análises de consubstancialidade e coextensividade, classe, raça e sexo são relações sociais estruturantes em qualquer desenvolvimento teórico, já quando se utiliza interseccionalidade, a geometria é variável, de modo que outras categorizações podem compor a multiposicionalidade, tais como religião, idade, nacionalidade etc.

Tanto Hirata (2014), Mojab e Carpenter (2019) quanto Smith (2017) chamam a atenção para o fato de que interseccionalidade é um conceito e não uma teoria. Da mesma forma, não consideramos que seja uma metodologia, conforme defende Akotirene (2018). Collins e Bilge (2021, p. 18) chamam de "ferramenta analítica" ou "ferramenta heurística ou de resolução de problemas". Arruzza denomina "abordagem" (Marcelino; Torre, 2021, p. 157). Interseccionalidade "é uma descrição de como diferentes formas de opressão - racismo, sexismo, homofobia e todas as outras formas - interagem umas com as outras e se fundem numa experiência única" (Smith, 2017, s.p.). Diz respeito à simultaneidade, sobreposição ou encadeamento de opressões. A própria Crenshaw (1993, s.p.) não considerava interseccionalidade uma teoria. Diz a estudiosa: "interseccionalidade não está sendo aqui apresentada como uma nova teoria totalizante da identidade". Collins

11 "Autoras que mobilizam o conceito de interseccionalidade frequentemente não desenvolvem de maneira aprofundada e objetiva sua compreensão de classe social, ou, por vezes é pouco precisa" (Roncato, 2020, p. 156) 
e Bilge (2021, p. 18), mencionando Cho, Chenshaw e McCall, defendem que "o foco deve ser 'o que a interseccionalidade faz e não o que a interseccionalidade é".

É importante enfatizar, contudo, que, apesar desse debate teórico e da necessidade de pensar práxis como junção de teoria e prática, há diferenças entre como interseccionalidade é mobilizada na luta social em contraste com o debate teórico. Bhattacharya exemplifica a diferença quando menciona que“[...] num campus dos EUA, se você ouvir uma jovem mulher dizendo que é uma feminista interseccional, é simplesmente uma abreviação para dizer que é um feminismo antirracista" (Bhattacharyaapud Marcelino; Torre, 2020, p. 158).

Conforme Mojab e Carpenter (2019), é comum ouvir de estudantes e jovens militantes que uma análise interseccional é uma ruptura radical com o feminismo branco liberal. As referidas autoras alertam que assim como conceitos como "empoderamento", "equidade", "elevação da consciência"12 foram apropriados por interesses burgueses e liberais, a interseccionalidade corre o mesmo risco, quando apresentada sem mediações, ao ponto de reproduzir condições que originalmente criticava.

Para elas, dois elementos explicam a limitação da interseccionalidade para ir além de uma análise de representatividade ou reconhecimento: o progressivo enfraquecimento da análise marxista para a relação entre capitalismo e patriarcado na década de 1980 e, ao mesmo tempo, a marginalização ou desaparecimento da classe social nas análises feministas, quando outras formas de opressões ganharam centralidade nas investigações.

Essa constatação se aproxima das preocupações de Collins (2017), de que a legitimação acadêmica da interseccionalidade a afastou das lutas políticas emancipatórias.

Uma maneira de conter o potencial emancipatório da interseccionalidade consiste em apropriar-se de suas ideias, reformulando-a em relação às agendas neoliberais, depois descartando-a ao apontar uma aparente impossibilidade de a interseccionalidade promover mudança (Collins, 2017, p.14).

Nossa hipótese se expande para além do fato da interseccionalidade ter sido institucionalizada academicamente e questiona como a categoria "classe social" foi mobilizada no período das décadas de 1980 e 1990, com a queda do muro de Berlim e a "morte de Marx", que significaram também o apagamento de uma

12 Consciousness raising. 
perspectiva revolucionária e perda de legitimidade da teoria marxista no interior do mundo acadêmico. Em concordância com Roncato (2020), há uma percepção de que "classes sociais" não são mobilizadasna perspectiva marxista, enquanto bases estruturais da sociedade em constante movimento, mas como estratificação social, conforme aventamos anteriormente.

A preocupação de Collins (2017) gira em torno de justiça social e da democracia participativa, nada que abalasse as estruturas sociais. E nem esses elementos reformistas ela vê como horizonte na forma como a interseccionalidade está sendo parcialmente apropriada na atualidade no âmbito acadêmico, que ela reconhece como profundamente neoliberal.

Mais uma vez, ressaltamos que a incorporação institucional não foi imediatamente uma apropriação de defesa do status quo, bem como não se restringiu ao debate da interseccionalidade. Vogel (2013) explicou que a década de 1980 foi marcada por um clima político conservador e pela derrocada de muitos movimentos sociais radicais, tendo o trabalho intelectual feminista em geral sofrido uma série de restrições e pressões profissionais, o que impactou, também, na perda de relevância do pensamento socialista para a teoria feminista como um todo. "O dilema fundamental da incorporação institucional está na tensão entre visar a provocar a transformação institucional e, ao mesmo tempo, reconhecer que trabalhar para a mudança social nos muda" (Collins; Bilge, 2021, p. 117).

Deriva dessas constatações uma importante distinção feita por Smith (2017), de que é preciso observar cautelosamente as bases teóricas que fundamentam a abordagem de interseccionalidade: se enraizada no feminismo negro ou no pós-modernismo/pós-estruturalismo.

A mencionada distinção é muito importante, porque geralmente o pós-modernismo é apresentado como a antítese do marxismo e, exatamente por isso, muitos marxistas rechaçam a ferramenta analítica de interseccionalidade, ignorando que os elementos que a fundamentam no feminismo negro têm fortes alicerces em práticas políticas revolucionárias, com feministas que abertamente se reivindicavam marxistas. Isso pode ser observado, por exemplo, no Manifesto de Combahee River:

Percebemos que a libertação de todos os povos oprimidos exige a destruição dos sistemas político-econômicos capitalistas e imperialistas, bem como do patriarcado. Somos socialistas por acreditarmos que o trabalho deve ser organizado para o benefício coletivo daqueles que trabalham e criam os produtos, e não para o lucro dos patrões. Os recursos materiais devem ser igualmente distribuídos 
entre aqueles que os criam. Não estamos convencidas, contudo, de que uma revolução socialista que também não seja uma revolução feminista e antirracista garantirá nossa libertação. [...] Embora concordemos, em essência, com a teoria de Marx, uma vez aplicada às relações econômicas muito específicas por ele analisadas, sabemos que sua análise deve ainda ser expandida para que possamos compreender nossa situação econômica específica enquanto mulheres negras (Combahee River, 2019, p. 201).

Angela Davis, que, desde muito cedo, concebeu uma análise social que encadeasse as experiências de classe, raça e sexo (Davis, 2016), lutou enquanto Pantera Negra e se reivindicava comunista. Mas, principalmente, com a institucionalização do feminismo negro na academia, a interseccionalidade passou a colocar menos ênfase na classe social.

Junto com o neoliberalismo, o pós-modernismo ganha relevância como explicação teórica no mundo acadêmico especialmente a partir da década de 1990. "A predisposição de etiquetar tudo com o prefixo 'pós' sugere que, no início do século XXI, estamos em um período "depois" dos projetos emancipatórios que aspiram à liberdade" (Collins, 2017, p. 15).

Smith (2017) nos recorda de que o pós-modernismo tem impacto no que diz respeito a conquistas na luta contra opressões, algo que, apesar de já ter aparecido nas teorias hegemônicas até então, de base iluminista, permanecia secundarizado. Mas o acento no local, na diferença, na ênfase exagerada na subjetividade e na recusa de temas universais tem consequências para a práxis política.

Outro elemento que as feministas materialistas já tinham sinalizado e que Smith (2017) reforça é a diferença entre identidade social e identidade individual, destacando que os pós-modernos e os pós-estruturalistas se centram, na maior parte dos casos, na perspectiva individual. E quando falam da diferença, também é da perspectiva individual.

A mais recente evolução da abordagem pós-estruturalista no âmbito da política de identidade e interseccionalidade, que vem tendo uma forte influência na atual geração de ativistas, coloca uma enorme ênfase na mudança dos comportamentos individuais como uma das formas mais efetivas no combate à opressão (Smith, 2017, s.p.).

Smith (2017) não tem o objetivo apenas de apontar essas diferenças, mas também de alertar que há marxistas que perdem a perspectiva da luta social ao 
rechaçar qualquer análise que se utilize da conceituação da interseccionalidade, sem entender que existem apropriações diferentes do conceito, e que a interseccionalidade que nasce do feminismo negro combativo da década de 1970 tem um grande potencial transformador.

\section{PARA ALÉM DOS SISTEMAS DUPLOS E/OU TRIPLOS, UMA ONTOLOGIA INTEGRATIVA}

Se o conceito de interseccionalidade, alicerçado no feminismo negro, e o conceito de consubstancialidade, concebido pelas feministas materialistas francesas, procuram superar análises parciais das opressões na sociedade capitalista contemporânea, as feministas da Teoria da Reprodução Social também o fazem, no sentido de propor uma teoria unitária, que não pressuponha classe, raça e sexo como sistemas em separado, mas que articule e explique a "experiência diferenciada-mas-unificada das múltiplas opressões” (Ferguson, 2017, p. 15, grifos nossos).

As análises conceituadas a partir da interseccionalidade e da consubstancialidade parecem carecer do fundamento ontológico que explique as relações sociais no capitalismo, a partir da dialética entre universal, particular e singular.

A solução para os problemas até aqui apontados não pode se bastar em apenas adicionar a categoria "classe social" nos desenvolvimentos teóricos, mas entender como as relações sociais se estruturam, na particularidade do tempo presente, na dialética entre o concreto dessas relações, com suas singularidades e particularidades, e a totalidade social, historicamente constituída e repleta de contradições.

Ainda que Crenshaw (1993) faça a crítica da hipervalorização da diferença, que nega a identidade, as suas explanações se centram em análises empíricas que revelam as opressões em jogo em espaços-tempo localizados. Collins e Bilge (2021, p. 51) alertam que "a generalização da interseccionalidade a partir de um caso particular ou das experiências de um grupo em um contexto social específico corre o risco de perder o processo de estruturas interseccionais". Para não perder de vista essa relação entre caso particular e estruturas, a proposta é colocar acento nas intersecções, ao invés de nas mediações entre singularidade e totalidade social.

As teóricas que se utilizam da noção da interseccionalidade dificilmente fazem estudos sobre as bases estruturais das opressões de forma integrada. Ferguson (2017) chama a atenção para o fato de que, em algumas pesquisas conceituadas a partir da interseccionalidade, patriarcado e colonialismo podem até se interseccionar, mas são concebidos como ontologicamente diversos, como sistemas distintos. 
O elemento da solidariedade também aparece no campo político da interseccionalidade, mas como algo contingente, em uma lógica aditiva das discriminações, de experiências compartilhadas, enquanto que uma análise com base na totalidade social, desvendaria as raízes sócio-materiais dessa solidariedade (Ferguson, 2017). Ou seja, análises diferenciadas de solidariedade acarretam em implicações políticas diversas.

As feministas materialistas francesas, ao proporem a conceituação de consubstancialidade, têm o intuito de analisar as relações sociais em sua dinâmica, sem perder de vista a historicidade. "O suposto paradoxo aponta para a imbricação, na própria gênese da divisão sexual do trabalho produtivo e reprodutivo, de diferentes relações sociais [...]” (Kergoat, 2010, p. 94). Ou seja, ao invés de intersecção, adição ou justaposição, a consubstancialidade aponta para uma imbricação de relações sociais de classe, raça e sexo.

Mas há algumas pressuposições das feministas materialistas, anteriores ao debate de consubstancialidade e interseccionalidade, que ratificam que classe, raça e sexo pertençam a sistemas diversos (Arruzza, 2017; Moraes, 2021). As relações de poder de cada uma dessas categorias teriam caráter de modo de produção, ou seja, além da classe social, haveria classe de sexo e classe de raça (Falquet, 2019). Todas juntas constituiriam uma totalidade. Contudo, é preciso lembrar que, na perspectiva teórica do marxismo, o todo não é a simples soma das partes.

$\mathrm{O}$ trabalho, que remete à produção e à reprodução, é central na Teoria da Reprodução Social porque garante a existência dos seres sociais. Daí os níveis de abstração das análises serem fundamentais. No nível fenomênico, o que se pode observar é que corpos que trabalham são diversos. Tal diversidade tem patamares de relevância a partir das necessidades do capital, daí que a generificação e racialização dos/das trabalhadores/as têm impacto no modo como o capital é produzido e reproduzido. Portanto, o uso da força de trabalho enquanto trabalho humano abstrato expressa a unidade na diversidade.

Podemos exemplificar melhor essa relação entre universalidade e particularidade se olharmos para quando Davis (2016), no debate sobre o trabalho doméstico, chama a atenção para o fato de que as mulheres negras não são donas de casa em tempo integral e que, portanto, a campanha do "salário para o trabalho doméstico"13 não tem o mesmo impacto estratégico político quanto para mulheres brancas de classe média. Inclusive, "nos Estados Unidos, as mulheres de minorias

13 Tal campanha teve origem na Itália, tendo tido seu primeiro protesto público realizado em 1974. Mariarosa Dalla Costa é um dos ícones do movimento (Davis, 2016). Outro nome importante da campanha é o de Sílvia Federici. 
étnicas - especialmente as negras - têm sido remuneradas por tarefas domésticas há incontáveis décadas" (Davis, 2016, p. 239). O Brasil, marcado historicamente pela escravidão, tem as mulheres negras remuneradas por trabalhos domésticos desde que puderam acessar o mercado de tralho, porém de maneira extremamente precária, dado que seus trabalhos são majoritariamente informais. Só estudos da história e das particularidades que envolvem a vida concreta dessas mulheres, negras e outras mulheres racializadas dos Estados Unidos ou das periferias do sul global, podem revelar suas relações contraditórias de exploração e opressões com a totalidade da acumulação capitalista.

Outro debate sobre o trabalho doméstico que envolve feministas da reprodução social desde a década de 1970 até os dias atuais é se o trabalho doméstico não remunerado gera ou não mais-valor (Vogel, 2013). Tal preocupação, em geral, tem relação com a busca pelo sujeito revolucionário. Uma concepção mais restrita (Federici, 2021) ou mais ampla (Bhattacharya, 2018) de classe trabalhadora terá repercussões diretas sobre o embate teórico. De novo, a resposta só pode vir da análise da realidade concreta, das peculiaridades sócio-históricas e suas mediações com a totalidade capitalista.

Uma análise de base ontológica suprassume noções de adição ou imbricação, avançando para análises dialéticas entre o todo e as partes. "Em outras palavras, tudo é socialmente mediado. Não há trabalho fora do gênero, raça ou capacidade, assim como não há gênero fora da raça, do trabalho e da sexualidade” (Arruzza, 2017, p. 30-1).

É importante dizer, conforme Arruzza (2017), que afirmar que o todo social é dominado pela dinâmica capitalista não é mesmo que dizer que o imperativo capitalista é absoluto, que ele é a base econômica que determina mecanicamente toda a ideologia de uma sociedade, ou que o capitalismo é a base, e o patriarcado é a sua superestrutura ideológica.

Com essa constatação, também se faz a crítica a marxistas economicistas que fazem uma leitura etapista da revolução social, priorizando a exploração frente às demais opressões, bem como não analisando opressão e exploração como concretamente integradas. A luta antissexista, antirracista, contra a LGBTTfobia ${ }^{14}$, por educação pública, saúde pública, anti-colonial ou qualquer outra que atinja a reprodução do capital afetará a formação social capitalista.

14 Utilizamos a sigla LGBTT (Lésbicas, Gays, Bissexuais, Travestis e Transgêneros), porém há outras variações que buscam contemplar de forma mais ampla a diversidade em torno da sexualidade, como é o caso de LGBTQIAP+, uma sigla que abrange pessoas que são Lésbicas, Gays, Bissexuais, Trans, Queer/Questionando, Intersexo, Assexuais/Arromânticas/Agênero, Pan/Poli, e mais. 
A percepção mais importante da teoria da reprodução social é que o capitalismo é um sistema unitário que pode integrar com êxito, ainda que desigualmente, a esfera da reprodução e a esfera da produção. Mudanças em uma esfera, então, reverberam na outra. Salários baixos e cortes neoliberais no trabalho podem produzir despejos e violência doméstica no lar (Bhattacharya, 2019, p. 104).

Se assim o é, não é possível falar de superação do capitalismo sem falar em superação das opressões e vice-versa. Isso não significa que tudo determina tudo, como fazem parecer as teóricas materialistas da consubstancialidade. Entender as determinações múltiplas e contraditórias do concreto é o exercício proposto pelo materialismo histórico-dialético.

A universalidade, sobretudo, não é jamais um ponto de chegada autônomo do pensamento. Marx, na introdução teórica [...] à primeira redação de sua obra econômica, fala de dois caminhos que o conhecimento humano deve percorrer: isto é, da realidade concreta dos fenômenos singulares às mais altas abstrações, e destas novamente à realidade concreta, a qual - com a ajuda das abstrações - pode agora ser compreendida de um modo cada vez mais aproximativamente exato. Aqui é preciso sublinhar, sobretudo para as nossas considerações, precisamente o caráter aproximativo da ciência (Lukács, 1970, p. 95).

A crítica ao "essencialismo marxista” feita pelos pós-modernos diz respeito a uma não compreensão do que seja universalidade em Marx. Equivocam-se em uma noção enrijecida e fetichizada de universal. É preciso "compreender a universalidade em uma contínua tensão com a singularidade, em uma contínua conversão em particularidade e vice-versa” (Lukács, 1970, p. 96).

Quando Arruzza (2015) chama atenção para que nos apropriemos corretamente do método de Marx, ela o faz no sentido de que muitos marxistas separam o lógico e o histórico enquanto elementos completamente distintos, de modo a apresentar um pensamento muito consistente do ponto de vista lógico, por exemplo, nas determinações da exploração e da produção de mais-valia, mas totalmente distanciado da história e do concreto. $\mathrm{O} / \mathrm{a}$ analista, ao mudar o nível de abstração e procurar observar no concreto aquela lógica que parecia tão passível de explicação, encontra determinações outras de descontinuidade na continuidade. Por exemplo: não há acumulação capitalista sem opressão e expropriação de mulheres e de pessoas racializadas. 
Aquela explicação lógica, que parecia ter uma coerência interna, encontra uma classe trabalhadora profundamente heterogênea, que sofre a exploração, a dominação e a alienação de formas diversificadas. Nesse nível de abstração, a hierarquização entre exploração e opressão encontra desafios explicativos na realidade concreta.

Perante tais desafios é que se encontram as feministas marxistas, em especial da Teoria da Reprodução Social, as quais entendem que precisam avançar suas análises sobre a sociedade capitalista, fortemente fetichizada, generificada e racializada.

Ela [a TRS] oferece uma chave interpretativa única para analisarmos a interrelação entre as múltiplas relações sociais que constituem as sociedades capitalistas, na medida em que permite considerar as relações econômicas e sociais como ontologicamente inseparáveis e integradas, i.e., como diferentes momentos de uma mesma totalidade social (Ruas, 2021, p. 410).

Nossa contribuição é que se atente para níveis de abstração e relação dialética entre a heterogeneidade da classes trabalhadora, com mulheres negras, brancas, migrantes, de várias faixas-etárias, origens étnicas diversas, com deficiência, trans, dentre outras, não de forma aditiva, interseccionada ou imbricada, mas ontologicamente constituída, observando as contradições existentes na relação dialética entre essas singularidades e a totalidade social capitalista, mediadas pelas particularidades, com seus determinantes estruturais e históricos sexistas, racistas e imperialistas.

\section{CONSIDERAÇÕES FINAIS}

Ao buscar, através do método materialista histórico-dialético, diferenciar a teoria unitária (TRS), em suas bases ontológico integrativas, de outras análises feministas de sistemas duplos ou triplos, buscamos, por um lado, ratificar a importância do rigor metodológico para o feminismo marxista, enquanto, por outro, explicitar como base teórica e prática social podem se aproximar ou distanciar nas suas expressões concretas. Conforme Bhattacharya (Marcelino; Torre, 2020, p. 153), a TRS nasce observando e aprendendo com os movimentos sociais e, mais recentemente, em diálogo com esses movimentos. A teoria oferece bases para sua práxis, através de intelectuais orgânicas/os.

Em um primeiro momento, consideramos relevante um debate teórico sobre o método em Karl Marx, com acento especial na relação entre universal, particular 
e singular, sob uma interpretação lukacsiana. Um problema que, na aparência, parece se bastar em uma análise lógica, mas que, em essência, explica as relações ontológico-integrativas da materialidade concreta, em especial, no que se refere à análise do capitalismo enquanto totalidade social. Essa apreensão teórica permite elevar à compreensão da conexão entre relações de opressão e produção capitalista (Ruas, 2021), não de forma etapista, mas através de determinantes determinados, em relação dialética entre bases socio-econômicas e ideológicas.

O conteúdo explicitado ganha mais nitidez com relação às teorias feministas ao serem feitas as críticas aos sistemas duplos e triplos a partir da teoria unitária da TRS. Primeiro, trabalhando a relação integrada entre capitalismo e patriarcado, ou opressão de gênero, de modo a explicitar as bases materiais deste último, assim como o caráter ideológico produzido pelo sistema capitalista, sem separá-los meramente como base (capitalismo) e superestrutura (patriarcado). Nesse debate teórico das décadas de 1970 e início da década de 1980, sobre as aproximações entre feminismo(s) e marxismo, a questão racial e do racismo estrutural estão à margem, ainda que presentes fortemente nas lutas sociais.

Discorremos sobre diferenças e similitudes das abordagens da interseccionalidade e da consubstancialidade. A interseccionalidade nasce das lutas concretas pela inseparabilidade do combate às opressões raciais, sexuais e classistas na década de 1970, e se conforma como conceito posteriormente, através de Crenshaw, na década de 1990, no sentido de combinações de opressões que se interseccionam, podendo expandir para além das mencionadas. A consubstancialidade, advém do arcabouço teórico das materialistas francesas, anterior à conceituação de interseccionalidade. É nos anos 2000 que Kergoat sistematiza uma crítica à interseccionalidade, diferenciando a imbricação de relações sociais de classe, gênero e raça à justaposição de opressões.

A TRS traz à tona a ideia de ontologia integrativa ao analisar a totalidade capitalista, que pensa produção de reprodução social como partes de uma unidade, ainda que repleta de contradições, e que analisa as opressões em geral, mas sem perder de vista suas particularidades. Nesse sentido,“[...] a verdadeira questão é como as relações de classe são estruturadas por meio de relações opressivas" (Bhattacharya apud Marcelino; Torre, 2020).

A partir da ideia de suprassunção, acreditamos que a perspectiva da totalidade e a análise a partir da ontologia integrativa avançam teoricamente para além de adição ou imbricação de relações de opressão. Não se trata de um mero debate teórico, mas olhar para o concreto como síntese de múltiplas determinações, e ver que não existe um ser social que não tenha classe, raça, gênero, sexualidade e 
que pode, além dessas determinações, sofrer opressões por outros determinantes históricos, os quais são organizados, hierarquizados e potencializados pela relação integrada entre produção e reprodução capitalistas.

O desenvolvimento teórico deste artigo alicerça a defesa de que o método se torna uma ferramenta imprescindível para a construção teórica no âmbito da Teoria da Reprodução Social integrada à luta revolucionária anticapitalista.

\section{REFERÊNCIAS BIBLIOGRÁFICAS}

ABREU, Maira; Castro, Bárbara (2019). Marxismos, feminismos, queer e sexualidades Parte I. Crítica Marxista, n. 48.

AKOTIRENE, Carla (2018). O que é interseccionalidade? Belo Horizonte: Letramento. ARRUZZA, Cinzia (2015). Considerações sobre gênero: reabrindo o debate sobre patriarcado e/ou capitalismo. Revista Outubro, n. 23.

ARRUZZA, Cinzia (2017). Funcionalista, determinista e reducionista: o feminismo da reprodução social e seus críticos. Campinas, CEMARX.

ARRUZZA, Cinzia (2019).Ligações perigosas: casamentos e divórcios entre marxismo e feminismo. São Paulo: Usina.

BHATTACHARYA, Tithi (2018). Como não pular a classe: reprodução social da força de trabalho e classe trabalhadora global. Medium, o7 mai. Disponível em $<$ https://medium.com/feminismo-com-classe/como-n\%C3\%A30-pular-a-classereprodu\% $3 \% \mathrm{~A} 7 \% \mathrm{C}_{3} \% \mathrm{~A} 30-$-social-da-for\%C $3 \% \mathrm{~A} 7 \mathrm{a}$-de-trabalho-e-classe-detrabalho-global-bcea36904835>. Acesso em 10 abr. 2021

BHATTACHARYA, Tithi (2019). O que é a teoria da reprodução social? Revista Outubro, n. $32,1^{\circ}$ semestre.

CISNE, Mirla (2014). Relações sociais de sexo, "raça"/etnia e classe: uma análise feministamaterialista. Temporalis, Brasília (DF), ano 14, n. 28, p. 133-149, jul./dez.

COLLINS, Patricia Hill (2017). Se perdeu na tradução? Feminismo negro, interseccionalidade e política emancipatória. Parágrafo, [S.l.], v. 5, n. 1, p. 6-17, jun. ISSN 2317-4919. Disponível em: <http://revistaseletronicas.fiamfaam.br/index.php/recicofi/article/ view/559>. Acesso em: 25 fev. 2020.

COLLINS, Patricia Hill; BILGE, Sirma (2021). Interseccionalidade. São Paulo: Boitempo. COMBAHEE RIVER (2019). Manifesto do Coletivo Combahee River. Plural, 26(1), 197-207. Disponível em: <https://doi.org/10.11606/issn.2176-8099.pcso.2019.159864>. Acesso em 28 de fevereiro de 2020.

CRENSHAW, Kimberle (1989). Demarginalizing the Intersection of Race and Sex: A Black Feminist Critique of Antidiscrimination Doctrine, Feminist Theory and Antiracist 
Politics. Universityof Chicago Legal Forum. Disponível em <https://chicagounbound. uchicago.edu/uclf/vol1989/iss1/8>. Acesso em o1 de março de 2020.

CRENSHAW, Kimberle (2017). Mapeando as margens: interseccionalidade, políticas de identidade e violência contra mulheres não brancas, Revista Subjetiva. Disponível em $<$ https://medium.com/revista-subjetiva/mapeando-as-margens-interseccionalidadepol\%C3\%ADticas-de-identidade-e-viol\%C3\%AAncia-contra-mulheres-n\%C3\%A3018324d40adif $>$. Acesso em o1 de março de 2020.

DAVIS, Angela (2016).Mulheres, raça e classe. São Paulo: Boitempo.

DELPHY, Christine (2015). O inimigo principal: a economia política do patriarcado. Rev. Bras. Ciênc. Polít., Brasília, n. 17, p. 99-119, Ago. Disponível em:<http://dx.doi. org/10.1590/o103-335220151704>. Acesso em: 30 Jan. 2020.

DEVREUX, Anne-Marie (2005). A teoria das relações sociais de sexo: um quadro de análise sobre a dominação masculina. Soc. estado, Brasília , v. 20, n. 3, p. 561-584, Dez. Disponível em <http://www.scielo.br/scielo.php?script=sci_arttext\&pid=So10269922005000300004\&lng=en\&nrm=iso >. Acesso em 25 Fev. 2019.

FALQUET, Jules (2019). A combinatória straight. Raça, classe, sexo e economia política: análises materialistas e decoloniais. Crítica Marxista, n. 48.

FEDERICI, Silvia (2021). O patriarcado do salário. São Paulo: Boitempo.

FERGUSON, Susan (2017). Feminismos interseccional e da reprodução social: rumo a uma ontologia integrativa. Campinas, CEMARX.

FERGUSON, Susan; mcnally, David (2017). Capital, força de trabalho e relações de gênero. Revista Outubro, n. 29, novembro.

GORENDER, Jacob (2013). Apresentação. In: marx, Karl. O capital. Livro I. São Paulo: Boitempo.

HARTMANN, Heidi (1983). El infeliz matrimonio entre marxismo y feminismo: hacia uma unión más progressista. Teorya y practica, 12-1, mimeo.

HIRATA, Helena (2014). Gênero, classe e raça Interseccionalidade e consubstancialidade das relações sociais. Tempo social, vol. 26, n. 1.

KERGOAT, Danièle (2010). Dinâmica e consubstancialidade das relações sociais. Novos estud. - CEBRAP, São Paulo, n. 86, p. 93-103, Mar. Disponível em <http://www.scielo. br/scielo.php?script=sci_arttext\&pid=So101-33002010000100005\&lng=en\&nrm =iso $>$. Acesso em 01 Mar. 2020.

LUKÁCS, Georg (1970). O particular à luz do materialismo dialético. In: Introdução a uma estética marxista: sobre a particularidade como categoria da estética. Rio de Janeiro: Civilização Brasileira. 
MARCELINO, Giovanna; torre, Bruna Della (2020). Por um novo casamento entre feminismo e marxismo. Entrevista com CinziaArruzza e TithiBhattacharya. Crítica Marxista, n. 51.

MARKUS, György (2015). Marxismo e Antropologia. O Conceito de "essência humana" na filosofia de Marx. São Paulo: Expressão Popular.

MARX, Karl (2012). O método da economia política. In: Grundrisse. São Paulo: Boitempo.

MARX, Karl (2013). O capital. Livro I. São Paulo: Boitempo.

MÉSZÁROS, István (2013). O conceito de dialética em Lukács. São Paulo: Boitempo.

MOJAB, Shahzad; carpenter, Sara (2019). Marxism, feminism, and "intersectionality". Journal of Labor and Society, n. 22.

MORAES, Lívia de Cássia Godoi (2021). Capitalismo e patriarcado em pauta: aproximações e distanciamentos entre feminismo e marxismo. In: fernandes, Vinicius T.; Esquenazi, Arelys; moraes, Lívia de Cássia G. (Orgs). Trabalho e práxis: novas configurações, velhos dilemas. Marília: Lutas Anticapital.

MORAES, Lívia de Cássia Godoi; esquenazi, Arelys (2020). Epistemologias, práxis e desafios conjunturais nas relações entre feminismo(s) e marxismo In: martuscelli, Danilo Enrico (org.) Os desafios do feminismo marxista na atualidade. Chapecó: Coleção marxismo21.

RANIERI, Jesus (2004). Introdução. In: marx, Karl. Manuscritos econômico-filosóficos. São Paulo: Boitempo.

RONCATO, Mariana Shinohara (2020). WorkingPoor japonês: trabalho imigrante dekassegui e suas transversalidades. Tese (doutorado em Sociologia). Instituto de Filosofia e Ciências Humanas da Universidade Estadual de Campinas. Campinas.

RUAS, Rhaysa Sampaio (2021). Teoria da Reprodução Social: apontamentos desde uma perspectiva unitária das relações sociais capitalistas. Revista Direito e Práxis, [S.l.], v. 12, n. 1, p. 379-415, mar. Disponível em: <https://www.e-publicacoes.uerj.br/index. php/revistaceaju/article/view/46086>. Acesso em: 03 abr. 2021.

SCOTT, Joan (2019). Gênero: uma categoria útil para análise histórica. In: buarque de hollanda, Heloísa (org). Pensamento feminista: conceitos fundamentais. Rio de Janeiro: Bazar do Tempos.

SMITH, Sharon (2017). Uma agenda marxista para a interseccionalidade. Blog Junho. 3 de agosto. Disponível em <http://blogjunho.com.br/uma-agenda-marxista-para-ainterseccionalidade/>. Acesso em 03 de março de 2020.

VOGEL, Lise (2013). Marxism and the oppression of women: toward a unitary theory. Chicago: Haymarket Books. 
VOGEL, Lise (2018). BeyondIntersectionality.Science\&Society Vol. 82, No. 2, abril. Disponível em <https://doi.org/10.1521/siso.2018.82.2.275 >. Acesso em 10 de março de 2021.

YOUNG, Iris (1992). Marxismo y feminismo, más alládel "matrimonio infeliz" (una critica al sistema dual). In: El cielo por assalto, año II, n. 4, mimeo. 